\title{
Isolation and Molecular Characterization of Mycobiota and Other Microbiota from Fingernails
}

\author{
Adeoti Olatunde Micheal $^{1,2,5}{ }^{\text {, }}$, Ponle Temitope Elisabeth ${ }^{1}$, Komolafe Kafilat Adenike ${ }^{1,4}$, \\ Adedokun Elisabeth Olajumoke ${ }^{1}$, Abiola Adebiyi ${ }^{1}$, Olufemi Samson Olutope ${ }^{1}$, \\ Adesina David Ademola ${ }^{1,3}$ \\ ${ }^{1}$ Department of Science Laboratory Technology, Microbiology Option, the Oke-Ogun Polytechnic, Nigeria \\ ${ }^{2}$ Department of Pure \& Applied Biology, Ladoke Akintola University of Technology, Ogbomosho, Nigeria \\ ${ }^{3}$ Department of Microbiology and Botany, University of Ibadan, Ibadan, Nigeria \\ ${ }^{4}$ Department of Zoology, Parasitology Unit, University of Ibadan, Ibadan, Nigeria \\ ${ }^{5}$ Cellular Parasitology Unit, Department of Zoology, University of Ibadan, Ibadan, Nigeria \\ Email address: \\ txy23m@yahoo.com (A. O. Micheal) \\ ${ }^{*}$ Corresponding author

\section{To cite this article:} \\ Adeoti Olatunde Micheal, Ponle Temitope Elisabeth, Komolafe Kafilat Adenike, Adedokun Elisabeth Olajumoke, Abiola Adebiyi, Olufemi \\ Samson Olutope, Adesina David Ademola. Isolation and Molecular Characterisation of Mycobiota and Microbiota from Fingernails. \\ International Journal of Clinical and Developmental Anatomy. Vol. 7, No. 1, 2021, pp. 1-5. doi: 10.11648/j.ijcda.20210701.11
}

Received: January 29, 2021; Accepted: February 27, 2021; Published: March 9, 2021

\begin{abstract}
This study was carried out to ascertain the hygienic practices among tertiary institutions study and also to isolate and identify microbiota from their thereby conduct molecular screening of fingernails for potential pathogens. A total of 300 nail samples carefully aseptically collected from 30 consented individuals include artificial and natural fingernails from both male and female students of The Oke-Ogun Polytechnic, Saki. The students' consent were sought for and other ethical issues were complied with as stipulated by the Institutional Ethical Committee. The fingernails were swabbed with sterile swab sticks and thereafter inoculated on the surface of suitably prepared media plates and sub-cultured to obtain pure isolates. Morphological and biochemical tests were carried out on the isolates to confirm the isolates. All students were found to harbour diverse microbes on their undernails. The microorganisms isolated include: E.coli 16.6\%, Staphylococcus aureus 22.2\%, Streptococcus spp 13.88\%, Bacillus spp 25\%, members of the Acinetobacter 2.77\%, Salmonella spp 13.88\%, Fungi $5.55 \%$. The suspected Fungi isolates were sent for sequencing for further identification and characterization. The highest prevalence was found to be more in females than in their male counterparts, which could be as a result of unhygienic practices especially nail-fixing related of artificial nails because those with artificial nails keep longer nails than keeping natural nails. This result further confirmed that fingernails are a possible reservoir of several microbes and could be implicated in the spread of more virulent microorganisms.
\end{abstract}

Keywords: Molecular Screening, Virulent, Artificial Nails, Microbiota, Fingernails, Unhygienic-practices

\section{Introduction}

Un-hygienic practices among all ages have variously contributed to food borne diseases and are known to contribute to both human morbidity and mortality in addition as health care costs. Besides, outbreaks of food borne disease, health care costs related to these outbreaks are enormous [1]. The body surface is continually in touch with environmental microorganisms and become ready colonized by certain microbial species, gram- negative and gram-positive pathogens in clinical specimens. It will be a spread of community or hospital acquired infections, including those of the tract, tract, wounds and burns, bacteremia neonatal meningoencephalitis, emphysema and osteomyelitis. Various infections via hands and fingernails. Contaminations of hands play a significant role in faecaloral transmission of diseases [2]. The unhygienic habits of most of the people result in the varied infections through 
hands and fingernails. $80 \%$ of the diseases related to the poor domestic and private hygiene. One in every of the ways of healthy living is hand hygiene $[3,4]$. Wachukwu et al. [4] find that artificial fingernails could function a way for transmission of pathogens to foods and causing nosocomial infections in patients. Hedderwick et al., [5] concluded in a very study that artificial fingernails were more likely to harbour pathogens, especially gram- negative bacilli and yeasts, than native nails. The hand is a significant vehicle of transmission of assorted microbes, as well as the enteric species [6]. Feculent contamination of hands is one among the vital route by that youngsters square measure exposed to morbid organisms [7]. Colleges and Universities square measure a perfect atmosphere for the unfold of infection and infectious diseases. Transmission of microorganism enteric infections via hands has vital consequences for college kids, as they are a lot of doubtless to require meal and water while not laundry hands, therefore, they are expose to risk of infection [8]. Hand washing culture has long been identified as a crucial practices in prevention [9]. Research on food borne epidemics have shown that poor hygienic practices by food vendors have been a contributing factor in disease transmission. According to earlier study conducted researches for Disease Control and Prevention (CDC), lack of proper hygiene of food vendors was responsible for more than $30 \%$ of outbreaks in the late eighties and early nineties [10]. The present study aimed at identification thereby further preventing the spread of diseases and infection through fingernails which are reservoirs for diverse microorganisms. It is generally expected that the target age group under study are the most studious where hygiene practices is expected hence the need for the present study.

\section{Materials and Methods}

\subsection{Collection of Samples}

A total of 300 swab from both hands samples were collected randomly from both hands of 30 students' volunteers belonging to volunteers in whom their consent had being sought for. The study was conducted at The Oke-Ogun Polytechnic, Saki using sterile cotton swab sticks robbed all over the undernails and transported immediately to the laboratory to prevent dryness and for further deterioration on the samples.

Preparation of Culture Media and Identification of Isolates

All media used were prepared according to each manufacturer's specification.

(i) Inoculation of Media

The already accustomed swab of the fingernails were patterned on the surface of ready media plates. The plates were then incubated at $37^{\circ} \mathrm{C}$ for twenty-four hours. The plates were discovered for growth and a colonial description of the isolates. Designated colonies were sub cultured on agar, such as Sabroaud glucose agar, and EMB agar to isolate pure culture. When analytic pure cultures, the isolates were additional known and defined by size, shape, and their reaction to Gram's stain. (ii) Isolation and Identification Methods.

All the samples were primarily plated onto nutrient agar medium being general purpose medium. Demographic detailed information was collected based on sex, length and types. Sex (male and female), length (short and long), types (artificial and natural) from each respondent. The plated cultures were incubated at $37^{\circ} \mathrm{C}$ and checked for bacteria in 18-24 hours while suspected selected fungi plates were allowed growth until 48 hours. Separate colonies were sub cultured to obtain pure culture. Morphological and cultural characteristics of colonies were based on Gram staining techniques and biochemical tests [11].

(ii) Identification of Bacteria and Fungi

Further colonial morphological studies were allowed to be sub-cultured onto other selective and differential agar media such as Eosin Methylene Blue agar (EMB), Sabroaud Dextrose agar, Simon's Citrate Agar, Salmonella Shigella agar, MRS and incubated at $37^{\circ} \mathrm{C}$ for 24 hours while Sabroaud Dextrose agar waited for 48-72 hours. Morphological and biochemical properties of the isolates were identified, evaluated and compared according to [12]. Several biochemical identification methods such as Gram stain, indole test, oxidase test, catalase test were conducted for identification of the isolate [13].

\subsection{Gram Staining Techniques}

Prepare a clean smear from the pure culture of the organism which is less than 24 hours old and pass it through the flame in two times to heat fix the smear. To the already prepared thin smear, add few drops of crystal violet for 1 minutes before it is rinsed with water. The smear was flooded with Lugol's Iodine for 30 seconds and rinsed with water. A few drop of safranin stain was added after it was decolourized with $70 \%$ alcohol. The smears were placed respectively on a microscope and observed under oil immersion objective lens.

\subsection{Oxidase Test}

A piece of filter paper was soaked with few drops of oxidase reagent. Sterile inoculating loop was used to pick a colony of the test organism and smeared on the filter paper. If the organism is oxidase producing, the Phenylenediamine in the reagent will be oxidized to a deep purple colour.

\subsection{Molecular Analysis Technique}

\subsubsection{Fungal/Bacteria DNA Extraction}

Two milliters ( $2 \mathrm{mls}$ ) of suspected plant life cells broth was more to a metallic element BashingTM lysis Tube. 750 $\mu 1$ lysis resolution was more to the tube. It absolutely was secure in a very bead fitted with $2 \mathrm{ml}$ tube holder assembly and was processed at most speed for $>5$ minutes. The metallic element bashing BeadTM Lysis Tube was centrifuged in a very microcentrifuge at $>10,000 \mathrm{x} g$ for one minutes. It absolutely was transferred up to $400 \mu 1$ 
supernatant to a Zymo-spin Tm IV Spin filter (orange top) in a very assortment tube and was centrifuged at 7, $000 \mathrm{x} g$ for 1 minute. $1,200 \mu \mathrm{l}$ of fungal/bacterial deoxyribonucleic acid binding buffer was more to the filtrate within the assortment tube from step four. $800 \mu 1$ of the mixture from step five was transferred to a Zymo-spin Tm IIC column in a very assortment tube and was centrifuged at $10,000 \mathrm{x} g$ for one minute. The flow through from the gathering tube was discarded and the step was repeated. $200 \mu 1$ deoxyribonucleic acid pre- wash buffer was more to the Zymo-spin Tm IIC Column in new assortment tube and was centrifuged at 10 , $000 \mathrm{x} \mathrm{g}$ for one minute. $500 \mu \mathrm{l}$ fungal/bacterial deoxyribonucleic acid wash buffer was more to the Zymospin Tm IIC column and centrifuged at 10,000 x g for one minute. The Zymo-spin Tm IIC column was transferred to a clean $1.5 \mathrm{ml}$ microcentrifuge tube and $100 \mu 1$ ( $35 \mu 1$ minimum) deoxyribonucleic acid extraction buffer was more on to the column matrix. This was absolutely was centrifuged at $10,000 \times \mathrm{g}$ for thirty seconds to elute the DNA.

\subsubsection{Electrophoresis for DNA and PCR}

One gram (1g) of agarose (for DNA) and $2 \mathrm{~g}$ of agarose for PCR was measured. Agarose powder with $100 \mathrm{~mL} 1 \mathrm{TAE}$ was mixed in a microwavable flask. It was microwaved for 1-3 minutes until the agarose is completely dissolved. Agarose solution is allowed to cool down to ab for 5 minutes. $10 \mu \mathrm{l} \mathrm{EZ}$ vision DNA stain was added. EZ vision binds to the DNA and it allows to visualized the DNA under ultraviolet (UV) light. The agarose was poured into a gel tray with the well comb in place, newly poured gel was placed at $4{ }^{\circ} \mathrm{C}$ for $10-15$ minutes or allowed to sit at room temperature for 20-30 minutes until it has completely solidified.

\subsubsection{Loading Samples and Running Agarose Gel}

Loading buffer is added to each of the DNA samples or PCR products. When it was solidified, the agarose gel was placed into the gel box (electrophoresis unit). The gel box was filled with 1 TAE (or TBE) until the gel is covered. A molecular weight ladder is carefully load into the first lane of the gel. The samples was carefully load into the additional wells of the gel. The gel was run at $80-150 \mathrm{~V}$ for about1-1.5 hours. The power was turned OFF, the electrode was disconnected from the power source, and the gel was carefully removed from the gel box. The DNA fragments or PCR product was visualize under UV trans illuminator.

\subsubsection{PCR Mix Components}

The PCR cocktail contains12.5ul of Taq 2X as has been conditioned from England Biolabs (m0270); Also, the kit contain $1 \mu \mathrm{l}$ each of $10 \mu \mathrm{lM}$ forward and reverse primers; $2 \mu \mathrm{l}$ of DNA template and then made up with $8.5 \mathrm{ul}$ nuclease free water.

Primer Sequences for Bacterial identification

Forward primer

AGAGTTTGATCMTGGCTCAG

Reversed primer

sequences:

AAGGAGGTGWTCCARCCGCA

\subsubsection{Cycling Conditions}

Initial denaturation at $94^{\circ} \mathrm{C}$ for 5 minutes, followed by 36 cycles of denaturation at $94^{\circ} \mathrm{C}$ for 30 seconds, annealing at $55^{\circ} \mathrm{C}$ for 30 seconds and elongation at $72^{\circ} \mathrm{C}$ for 45 second. Followed by a final elongation step at $72^{\circ} \mathrm{C}$ for 7 minutes and hold temperature at $10^{\circ} \mathrm{C}$ forever. The lids are replaced and after solidification. The agar plates are incubated $30^{\circ} \mathrm{C}$ for 24-48 hours in bacterial, and fungal colony forms counter and expressed as $\mathrm{cfu} \times 106 / \mathrm{g}$. Data represented in the table.

\subsection{Statistical Analysis}

The statistical analysis was performed by using SPSS version for the analysis of data collected.

\subsection{Ethical Considerations}

The confidentiality of data collected was kept very intact and other ethical issues were complied with as stipulated by the Institutional Ethical Committee.

\section{Results}

Microbial contamination of undernails has become a global health problem thus a total of 30 under nails swabs from the undernails in left and right hands of 30 students of The Oke-Ogun Polytechnic, Saki were collected. All students were found to harbour bacteria on their undernails. Bacterial pathogens isolated from the under nails of students include both gram positive and gram negative bacteria. Grampositive isolates were Staphylococcus aureus, Bacillus spp, Streptococcus while the gram-negative bacteria include E.coli, Acinetobacter spp, Salmonella spp.

Table 1 shows the percentage of probable organisms isolated from the samples collected from undernails after calculating the percentage of each isolate. It was observed that the prevalence of E.coli $16.6 \%$, Staphylococcus aureus $22.22 \%$, Streptococcus spp 13.88\%, Bacillus spp 25\%, Acinetobacter spp $2.77 \%$, Salmonella spp $13.88 \%$, Fungi $5.55 \%$ are a greater concern for health. These colonies isolates were identified using biochemical tests, colony morphology and staining techniques with their reaction to Gram stain which categorized them into gram positive and gram negative respectively. Table 2 shows the morphological and biochemical characteristics of probable isolates under the finger nails in which E.coli was gram negative, having a rod like shape and biochemical test testing indole positive $(+)$, oxidase (-) and catalase positive (+). Staphylococcus aureus was gram positive having a cocci shape and its biochemical tests testing indole negative, oxidase positive, catalase positive. Staphylococcus was gram positive having a cocci shape and its biochemical test having indole negative, oxidase negative and catalase negative. Bacillus spp was gram negative having a bacilli shape and its biochemical test testing indole negative, oxidase negative and catalase positive. Opportunistic pathogens such as bacteria, viruses and fungi can survive on inanimate surfaces for long periods and items such as watches, pens and mobile phones are 
permanent surfaces of transmission of this type of infections [13]. Table 3 showed the isolates result from under nails of female and male and it was found out that the highest prevalence was found in female. Table 4 also shows the percentage of the isolates from under the fingernails. The results showed that high contaminations were found in females than in males, which could be as a result of artificial nails being fixed by female and keeping of long nails because artificial and long nails harbour more microorganisms than short nails. Table 5 shows the growth of fingernails samples on media. Long nails were found to have much more growth on media because long nails are prone to harboring pathogens. Short nails was found to have medium growth which could be as a result of unhygienic practices such as improper washing of hands after visiting the toilet, taking care of household pets which could lead to the contamination of the fingernails.

Table 1. Morphological and Biochemical profiles of isolates from under nails samples.

\begin{tabular}{llllll}
\hline $\begin{array}{l}\text { Gram } \\
\text { stain }\end{array}$ & Shape & $\begin{array}{l}\text { Indole } \\
\text { test }\end{array}$ & $\begin{array}{l}\text { Oxidase } \\
\text { test }\end{array}$ & $\begin{array}{l}\text { Catalase } \\
\text { test }\end{array}$ & $\begin{array}{l}\text { Probable } \\
\text { organism }\end{array}$ \\
\hline- & Rod & + & - & + & E.coli \\
+ & Cocci & - & + & + & S. aureus \\
+ & Cocci & - & - & - & Streptococcus \\
+ & Bacilli & - & - & + & Bacillus spp \\
- & Bacilli & - & - & + & Acinetobacter \\
- & Rod & - & - & + & Salmonella \\
\hline
\end{tabular}

Keywords: + Reaction, - No reaction.

Table 2. Severity of Growth of fingernails samples on Culture Media.

\begin{tabular}{ll}
\hline Types of nails & Growth on media \\
\hline Long nails & +++ \\
Short nails & ++ \\
Artificial nails & ++++ \\
\hline
\end{tabular}

Table 3. Isolates from undernails of participants per gender.

\begin{tabular}{lll}
\hline Microbiota isolated & Females n (\%) & Males n (\%) \\
\hline E.coli & $10(16.16)$ & $6(15.00)$ \\
S. aureus & $12(19.12)$ & $8(20.00)$ \\
Streptococcus & $10(16.12)$ & $4(10.00)$ \\
Bacillus spp & $14(22.58)$ & $10(25.00)$ \\
Salmonella spp & $8(12.90)$ & $6(15.00)$ \\
Acinetobacter & $4(6.45)$ & $2(10.00)$ \\
Fungi & $4(6.45)$ & $4(5.00)$ \\
Total & $62(60.8)$ & $40(39.2)$ \\
\hline
\end{tabular}

Table 4. Percentage of isolates from undernails samples.

\begin{tabular}{lll}
\hline Isolates & Number & Percentage (\%) \\
\hline E.coli & 12 & 16.66 \\
S. aureus & 16 & 22.22 \\
Streptococcus spp & 10 & 13.88 \\
Bacillus spp & 18 & 25.00 \\
Acinetobacter spp & 2 & 2.77 \\
Salmonella spp & 10 & 13.88 \\
Fungi & 4 & 5.55 \\
Total & 72 & 100 \\
\hline
\end{tabular}

Table 5. Prevalence of isolates from female and male respondents.

\begin{tabular}{lll}
\hline Isolates & Female \% & Male \% \\
\hline E.coli & 16.12 & 15.00 \\
S. aureus & 19.35 & 20.00 \\
Streptococcus & 16.12 & 10.00 \\
Bacillus spp & 22.58 & 25.00 \\
Salmonella spp & 12.90 & 15.00 \\
Fungi & 6.45 & 10.00 \\
Acinetobacter & 6.45 & 5.00 \\
\hline
\end{tabular}

Accession Number: EU645733

Aspergillus aculeatus Strain JO6

Isolate Molecular Sequences

GTTCAAAGCTTCATCCTCGATTTATGGATGGCCATC TGGTGACGAGTTTTGCCCCGGCCGGGCCTTAGAGCG GGTGACAGAGCCCCATACGCTCGAGGACCGGACGG $\mathrm{T}$

GCCGCCGTTTCTCTCGAGGCCCGCCCCCGGGAGG

CGCGGCGAGCAACCAGCGG

GCCTGGAGGGGAGAAATGACGCTCGGACAGGCAT GCCCCCCGGAATACCAGGG

GGCGCAATGTGCGTTCAAAGACTAAATGATTCACT

GAATTCTGCAATTCACATTA

ATTATCGCATTTCGCTGCGTTCTTCATCGATGCCGG

AACCAAGAGATCCATTGTG

GAAAGTTTTGACTGATTGATATCAATCGACTCAGA

CTGCACGCTTTCAGACAGTG

TTCCATTGGGGTCTCAGGCGGGCGCGGTCCCGGG

GGCAGGCCCCGGGCCGCCCG

CCCCCGAAAGGAACCAGCACTCGGTAATGATCCTT

CCGCAGGTTCACCTTACGGA

AACCTTTTTACACTTTTATTTCAAT

\section{Discussion}

Artificial nails were determined to harbour extra microbes, having numerous increase on media due to the fact fingernail duration and texture the performance of microbial elimination from underneath the nails. Long and polished nails usually harbour extra microbe even after hand washing hence, carrying artificial nails may be an issue influencing the efficacy of hand washing because synthetic nails commonly polished are commonly longer than natural nails. Thus, synthetic nails serves as a reservoir of microorganisms and are extra at risk of get contaminated than natural nails. Lau et al., opined that lengthy nails tend to harbor greater microorganisms than brief nails. Visibly smooth nails were located merely by using look of fingernails of students, showed presence of $62 \%$ bacterial infection on their palms. Ray et al., confirmed a lower in colony depend following hand washing with cleaning soap in $60 \%$ of the samples. Tambekar et al., Also discovered highest bacterial infection $(70 \%)$ was discovered in the palms of the kingdergaten students followed via $67 \%$ at the fingers of number one students, $66 \%$ on secondary college students, and $64 \%$ on Post-graduate students and at the least $57 \%$ at the hands of undergraduate students. Ray et al., observed that hand swab samples of $61 \%$ children harbour capacity pathogens before 
taking food, also mentioned presence of pathogenic microbes on the fingers of the scholars which consist of $S$. Aureus, E. coli, Pseudomonas spp, Klebsiella spp. This work was similar to the work by Akinwumi and others isolated pathogenic bacteria from their study on cell phones [14] and $[15,16]$, showed the presence of E. coli, Pseudomonas spp, Salmonella spp, Enterobacter spp and $S$. aureus from the hand swab samples of students. The presence of gram negative bacteria in fingernails may also explain contamination of faecal material. The frequency of organisms isolated was extra in artificial nails than herbal nails and will harbour diverse microorganisms. Four fungi isolates were isolated from undernails of the scholars and morphological and biochemical tests were executed on the isolates wherein one was tough to confirm. The isolate was dispatched for sequencing for further identity and characterization. The presence of $E$. coli may explain contamination of faecal material, which may be because of unhygienic practices, or even fallacious washing of palms after going to the toilet, managing domestic animals together with goats, dogs, ducks, fowls that are vulnerable to motive sickness and infection. The detection of $S$. aureus from fingernails of college students may also pose considerable health threat on college students as those organisms are able to generating enterotoxins that causes food poisoning, which can cause the malfunctioning of the body gadget and may even lead to death. The detection of Salmonella from fingernails could be an outright possible indication of food-borne infections among the Polytechnic students as result of their unkempt habit of purchasing and meal sharing without proper hand washing hygiene.

\section{Conclusion}

Fingernails remain one of the channel of food contamination and it serves as probable reservoir for pathogenic organisms in this study especially the females who prepare meals for both domestic and commercial purpose

\section{Acknowledgements}

We greatly acknowledge and appreciate the voluntariness of all participants in this project as well as the Medical Health centre staff of the Institution.

\section{References}

[1] Bean N. H., Goulding J. S, Lao, C and Angulo, F. J. (1996) Surveillance and food borne diseases outbreak, United States, Morbidity and Mortality Weekly Report. 45: 1-55. Res 3 (12): 2009-2012.
[2] Ray S. K, Amarch and R, Srikanth J. and Majumdar K. K (2011). A study on the prevalence of bacteria in the hands of children and their perception on hand washing in two schools of Bangalore and Kolkota. Indian journal of public health, 55 (4): 293-297.

[3] Patel H. R, Daniel P. S, Anand I. S and Patel C. N. (2010). Role of community pharmacist in assessing the awareness of hand hygiene in rural area. Journal of Global Pharma.

[4] Wachukwu C. K, S. D Abbey, A. O Ollor and Obilor N. L (2007). Public health implication of artificial fingernails used by health workers and food handlers in Port Harcourt, Nigeria. Journal of Applied Sciences. 7: 3580-3583.

[5] Hedderwick S. A, Mcweil S. A, Lyons M. J (2000) Pathogenic organisms associated with artificial fingernails worn by health care workers. Infect control Hospital Epidemiological. 21 (8) 505-509.

[6] Prescott L. M Harley J. P, Klein D. A (2005). Microbiology $6^{\text {th }}$ ed. Tim Migram-Hill co. New Delhi PP: 675.

[7] Langford RM, 2009. Handwashing and its impact on child health in Kathmandu, Nepal. Doctoral thesis, Durham University.

[8] Lau CH, Spriston E. E, Sohn M, Mason I, Gadola E, Damitz M. Lin C, Wu F. M, Doyle M. P, Micheal B. S and Williams K. (2002). Removal of Escherichia coli on hands with natural and artificial fingernails. International J. Epidemiological 21: 1157-1164.

[9] Larson E. 2001. Hygiene of the skin When is clean too clean? Journal of emerging infectious diseases. 7 (2) 12-17. Technology, 2 (5): 59-61.

[10] Ray S. K, Dobe M, Lahiri A and Basu S. S (2009) Handwashing practices in urban and rural communities in and around Kolkota, West Bengal Indian J Public health 53: 11921195.

[11] Cheesbrough M., (2006). District Laboratory Practice in Tropical Countries. $2^{\text {nd }}$ Edition. Cambridge University Press, Cambridge, (178-179.

[12] Ramos J. L (2004) Pseudomonas New York: Kluwer Academic/plenum publishers, $\mathrm{p}$.

[13] Ekrakene T. And Igeleke C. L (2007). Microorganisms associated with public mobile phones along Benin-Sapele express way, Benin City, Edo state of Nigeria J. Appl. Sci.

[14] Akinyemi K. O, Atapu A. D, Adetona O and Coker, A. O (2009). The potential role of mobile phones in the spread of bacterial infections, Journal. Infectious Dev Ctries. 318: 628632 .

[15] Tambekar D. H, Shirshat S. D, Kakde S. R and Ambekar K. B. (2009) Hand hygiene and health: an epidemiological study of students in Amravati. Africa Infection Diseases 3 (1): 26-30.

[16] Tambekar D. H and Shirshat S. D (2012) Minimization of illness absenteeism in primary students using low cost hygiene interventions. Journal of Health and Applied Sciences. 